\title{
Produtos naturais aplicados para manejo de Meloidogyne incognita em tomateiros
}

\author{
Thiago Anchieta de Melo ${ }^{1 *}$, Ilka Márcia Ribeiro de Sousa Serra ${ }^{2}$, Gilson Soares da Silva ${ }^{2}$, Rosa Maria Souto de Sousa $^{1}$ \\ ${ }^{1}$ Graduando do Curso de Agronomia, Universidade Estadual do Maranhão, UEMA, CEP 65041-970, São Luís, MA; ${ }^{2}$ Departamento de Fitotecnia \\ e Fitossanidade, Universidade Estadual do Maranhão, UEMA, CEP 65041-970, São Luís, MA; *Parte da monografia do primeiro autor. \\ Autor para correspondência: Ilka Marcia Ribeiro de Souza Serra (ilka.tt@gmail.com) \\ Data de chegada: 17/05/2011. Aceito para publicação em: 01/05/2012.
}

1756

\section{RESUMO}

Melo, T.A.; Serra, I.M.R.S.; Silva, G.S.; Sousa, R.M.S. Produtos naturais aplicados para manejo de Meloidogyne incognita em tomateiros Summa Phytopathologica, v.38, n.3, p.223-227, 2012.

Este trabalho teve por objetivo avaliar o efeito de produtos naturais na expressão da resistência a Meloidogyne incognita em plantas de tomate produzidos organicamente. Os indutores Rocksil, Quitosana, Neemseto e Biopirol foram aplicados 5, 10 e 15 dias, em tratamentos independentes, antes da inoculação do patógeno através da pulverização foliar, utilizando-se duas dosagens para cada indutor. A inoculação do nematoide foi realizada 30 dias após o plantio, usandose 5000 ovos/ planta. Avaliando-se o número de ovos e o fator de reprodução, 30 dias após a inoculação, observou-se que todos os tratamentos diferiram estatisticamente da testemunha, impedindo o aumento da população inicial do patógeno. Dentre os indutores, o indutor silicatado Rocksil foi o que apresentou os melhores resultados para o controle da meloidoginose em todas as épocas de aplicação e em todas as dosagens. Contudo, plantas tratadas com o produto apresentaram baixos pesos de parte aérea sugerindo que houve um custo adaptativo de resistência. Considerando-se o fator de reprodução não foram observadas diferenças estatísticas quando comparadas a dosagem e época de aplicação entre os indutores, com exceção da Quitosana aplicada aos 5 dias antes da inoculação e do Neemseto aplicado aos 15 dias antes da inoculação do nematóide.

Palavras-chave adicionais: indução de resistência, indutores naturais, Meloidogyne incognita.

\section{ABSTRACT}

Melo, T.A.; Serra, I.M.R.S.; Silva, G.S.; Sousa, R.M.S. Natural products applied to the management of Meloidogyne incognita in tomato plants Summa Phytopathologica, v.38, n.3, p.223-227, 2012.

This study aimed to evaluate the effect of natural products on the expression of resistance to Meloidogyne incognita in organically produced tomato plants. The inducers Rocksil, Chitosan, Neemseto and Biopirol were applied at 5, 10 and 15 days as independent treatments before the pathogen inoculation by means of leaf spraying, using two levels for each inducer. The nematode inoculation was performed at 30 days after planting, using 5000 eggs/plant. Evaluating the number of eggs and the reproduction factor, at 30 days after inoculation, all treatments statistically differed from the control, preventing an increase in the initial population of the pathogen. Of the natural inducers, Rocksil showed the best results for controlling the root-knot nematode in all application times and at all levels. However, plants treated with the product had low shoot weights, suggesting that there was a fitness cost of resistance. Considering the reproduction factor, there were not statistical differences when the level and the application time were compared among natural inducers, except for Chitosan applied at 5 days before the nematode inoculation and Neemseto applied at 15 days before the nematode inoculation.

Additional keywords: resistance induction, natural inducers, Meloidogyne incognita.

A produção brasileira de produtos orgânicos vem crescendo de forma considerável nos últimos anos (1). No estado do Maranhão, a produção de alimentos orgânicos, especialmente de hortaliças, ainda é bastante limitada. A falta de informação por parte dos produtores, tecnologias e insumos adaptados a esse sistema de produção são apenas alguns exemplos do que ainda precisa ser vencido.

Dentre as hortaliças mais cultivadas organicamente, o tomateiro (Solanum lycopersicum L.), solanácea originária da zona andina da América do Sul, está em destaque. Em termos de produção nacional, o Brasil ocupa o sexto lugar no ranking da produção mundial desta hortaliça, com uma produção de três milhões de toneladas plantadas numa área de 57,6 mil hectares (2).

A meloidoginose é uma doença amplamente distribuída pelo globo e traz problemas a diversas espécies de interesse econômico, incluindo hortaliças. As plantas atacadas pelo nematoide das galhas-Meloidogyne spp. - apresentam crescimento reduzido e deficiência mineral acentuada, sintomas normalmente expressos em reboleiras. Na raiz é possível a visualização de galhas, formadas a partir da hipertrofia e hiperplasia celular decorrentes do processo de parasitismo do patógeno (21).

Pelos preceitos da agricultura orgânica, as doenças vegetais são problemas gerados pelo manejo equivocado dos agroecossistemas, sendo importante a adoção de medidas preventivas que recomponham ou preservem o equilíbrio biológico, evitando assim o surgimento ou agravamento dos problemas fitossanitários (7).

A resistência induzida pode ser entendida como um fenômeno onde a resistência das plantas contra fitopatógenos é induzida através de infecção localizada ou tratamento com componentes ou produtos 
microbianos, ou ainda pelo uso de compostos orgânicos ou inorgânicos (4). A atividade do agente indutor não é devida à ação antimicrobiana, ou a sua transformação em agentes antimicrobianos, mas sim devida à capacidade do mesmo em sensibilizar a planta e a mesma em ativar seus mecanismos de defesa estruturais e bioquímicos em resposta à presença de um patógeno em potencial (22).

Os fertilizantes de plantas com efeito de indutores abióticos de resistência, principalmente os silicatados como exemplo do Rocksil e os industrializados à base de produtos naturais como o Neemseto, óleo a base de folhas de nim (Azadirachta indica A. Juss.); a Quitosana, polissacarídeo obtido a partir da carapaça dos crustáceos e, o Biopirol, extrato pirolenhoso, fração aquosa obtida na destilação do alcatrão de eucalipto; tem mostrado grande potencial no controle de doenças de hortaliças. Contra fitonematóides, a resistência induzida em plantas pode variar de acordo com a espécie e o estado nutricional do hospedeiro, tipo de indutor e patógeno envolvido (3). Em plantas resistentes a Meloidogyne spp., a formação do sítio de alimentação é inibida principalmente pela reação de hipersensibilidade ou pela degeneração precoce deste sítio (18). Baseado nisso, o objetivo deste trabalho foi avaliar, em casa de vegetação, o controle da meloidoginose em tomateiro orgânico, com a da utilização de diferentes produtos naturais, além de, estudar o efeito desses produtos, em diferentes dosagens e épocas de aplicação.

\section{MATERIAL E MÉTODOS}

\section{Obtenção de Mudas}

As mudas de tomateiro foram produzidas a partir de sementes da cultivar Santa Cruz Kada Gigante. A semeadura foi realizada em bandejas de EPS (Poliestireno Expandido) de 200 células contendo substrato comercial orgânico, sendo após 15 dias as mudas transplantadas para vasos plásticos contendo $1,0 \mathrm{Kg}$ de mistura de solo esterilizado, esterco bovino curtido e substrato comercial orgânico para hortaliças na proporção de 2:1:1.

\section{Obtenção e preparo do inóculo}

Para multiplicação das populações de Meloidogyne incognita (Kofoid \& White) Chitwood foi utilizado tomateiro cv. Santa Cruz, com 20 dias de idade. Utilizou-se como inoculo suspensão de ovos, de uma população de $M$. incognita, raça 1, procedente do Laboratório de Nematologia da Universidade Estadual do Maranhão. As plantas inoculadas foram mantidas em condições de casa de vegetação no Laboratório de Fitopatologia da Universidade Estadual do Maranhão.

Os ovos de M. incognita, que constituíram o inóculo, foram obtidos de acordo com a técnica de Hussey \& Barker (12). O número de unidades por mililitro foi ajustado para a densidade de 1250 ovos na suspensão que foi dispensada na proporção de $4 \mathrm{ml} /$ planta.

\section{Aplicação dos produtos naturais em casa de vegetação}

Os produtos Rocksil, Quitosana, Neemseto e Biopirol foram aplicados 5, 10 e 15 dias, em tratamentos independentes, antes da inoculação do patógeno através da pulverização foliar, utilizando-se duas dosagens para cada indutor: Rocksil 15 e $20 \mathrm{~g} /$ litro de água, Quitosana 0,35 e $0,70 \mathrm{~g}$ / litro de solução de ácido acético $0,5 \%$, Neemseto 0,5 e 1\% e Biopirol 0,5 e 1,0\%.

A inoculação do nematoide foi realizada 30 dias após a semeadura. As plantas foram inoculadas com suspensão de ovos de $M$. incognita na proporção de 5.000 por planta. O inóculo foi vertido em torno do colo da planta, em sulco de aproximadamente $2-3 \mathrm{~cm}$ de profundidade e coberto, em seguida, com o próprio substrato.

O delineamento adotado foi inteiramente casualizado, em arranjo fatorial 3 (três épocas de aplicação) X 2 (duas concentrações) X 4 indutores, com quatro repetições por tratamento, sendo cada unidade experimental representada por um vaso com uma planta. A testemunha consistiu de parcelas não induzidas e inoculadas (testemunha inoculada), e outra 'testemunha absoluta', não induzida e não inoculada. Os dados foram submetidos à análise de variância e as médias comparadas pelo teste de Scott-Knott a 5\% de probabilidade.

Decorridos 30 dias da inoculação, as plantas foram retiradas do substrato, as raízes lavadas em água corrente, e determinados os pesos em gramas da parte aérea e da raiz, número de ovos por planta e fator de reprodução ( $\mathrm{FR}$ = população final/ população inicial). A técnica empregada foi de Hussey \& Barker (12). Para análise estatística, os dados relativos a números de ovos dos indivíduos foram transformados em $\log _{10}(x+1)$, utilizando o teste de Scott-Knott a 5\% de probabilidade para separação das médias, quando necessário.

A determinação do peso fresco da biomassa das raízes e parte aérea foi feita logo após a coleta.

Os dados foram submetidos à análise de variância e os testes de separação de médias de Scott-Knott $(\mathrm{p}=0,5)$ efetuados com o auxílio do programa ASSISTAT.

\section{RESULTADOS E DISCUSSÃO}

O processo de parasitismo do nematoide das galhas sobre as plantas cultivadas resulta, entre outras coisas, em plantas comprometidas quanto ao seu desenvolvimento vegetativo. Em relação ao peso, em gramas, de parte aérea, todos os tratamentos diferiram estatisticamente da testemunha absoluta apresentando pesos inferiores a esta e na maioria dos casos, superiores à testemunha inoculada (Tabela 1). Entre os produtos utilizados, o Neemseto na menor dosagem e em todas as épocas de aplicação, apresentou plantas com os maiores pesos para o parâmetro analisado e bom desenvolvimento vegetativo. Resultados semelhantes foram observados por Khan \& Saxena (13), os quais relataram o aumento do peso seco total de plantas de tomateiro parasitadas por $M$. javanica após a utilização de diversos produtos naturais e fontes de matéria orgânica, dentre estes o nim.

Entre as épocas de aplicação dos indutores, a Quitosana aplicada aos 15 dias antes da inoculação do patógeno (DAI), apresentou plantas com maior peso de parte aérea, fato também observado por Serra et al. (20) aplicando os mesmos produtos para o manejo de M. incognita em alface orgânico. Foram observadas ainda, diferenças significativas entre as épocas de aplicação do Biopirol nas duas dosagens. A utilização desse produto na concentração de $0,5 \%$ resultou em redução significativa do peso de parte aérea em plantas tratadas aos $15 \mathrm{DAI}$ e, ao ser utilizado na maior concentração de $(1,0 \%)$, plantas induzidas aos 10 e 15 DAI, apresentaram peso de parte aérea estatisticamente inferior às plantas induzidas $5 \mathrm{DAI}$, esses resultados podem estar relacionados com baixo efeito do Biopirol no controle do M. incognita (Tabela 1). Resultados semelhantes também foram observados por Serra et al. (20) quando testaram diferentes indutores naturais, entre eles o Biopirol, no controle de $M$. incognita em alface orgânico.

Com relação ao número de ovos e, conseqüentemente, o fator de reprodução, todos os tratamentos; em todas as doses dos indutores e épocas de aplicação utilizadas; diferiram estatisticamente da testemunha inoculada apresentando baixos valores para os parâmetros em questão, como pode ser observado nas Tabelas 2 e 3 . O indutor silicatado Rocksil foi o que apresentou o melhor efeito sobre o $M$. 
Tabela 1: Efeito dos produtos naturais sobre o peso, em gramas, da parte aérea de tomateiros produzidos organicamente, 30 dias após o parasitismo de Meloidogyne incognita.

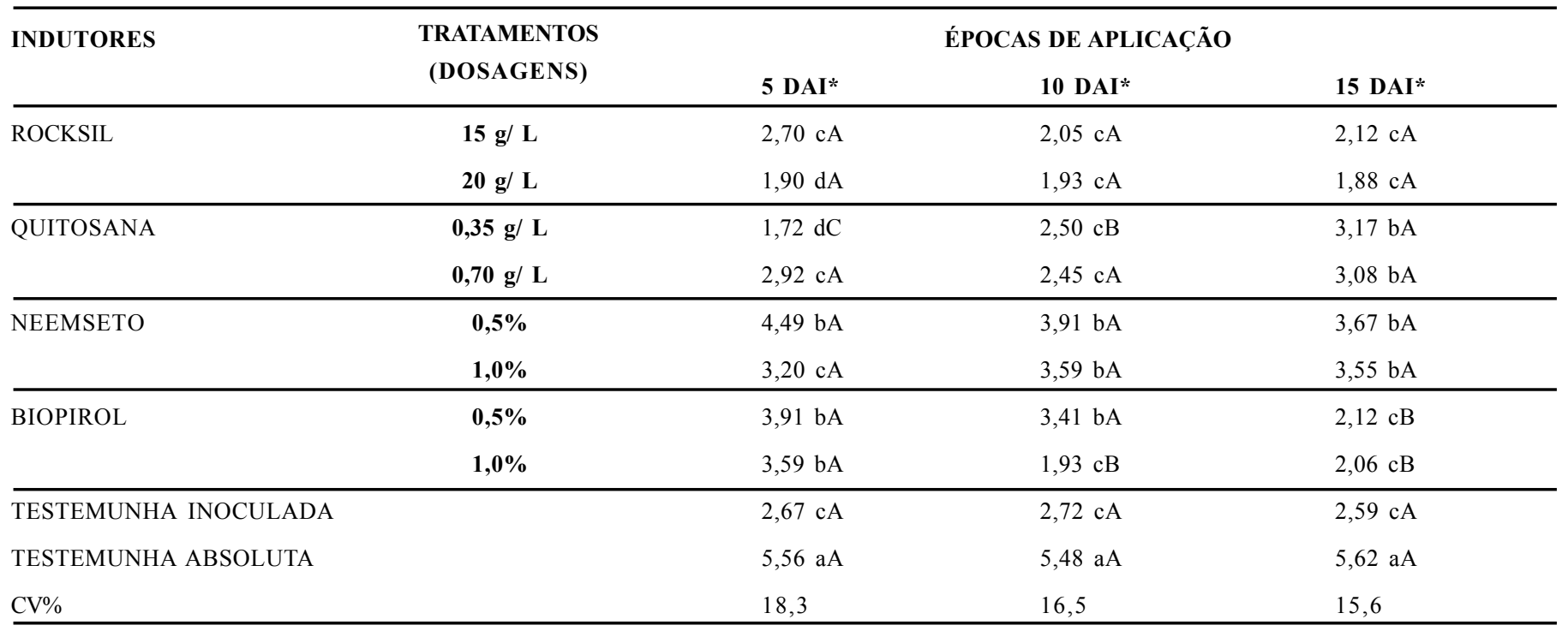

Médias seguidas pela mesma letra minúscula nas colunas e maiúscula nas linhas não diferem estatisticamente entre si pelo teste de Scott-Knott ao nível de $5 \%$ de probabilidade. *DAI - Dias anteriores à inoculação.

Tabela 2. Efeito dos produtos naturais sobre o número de ovos gerados 30 dias após a inoculação de Meloidogyne incognita em plantas de tomate orgânico.

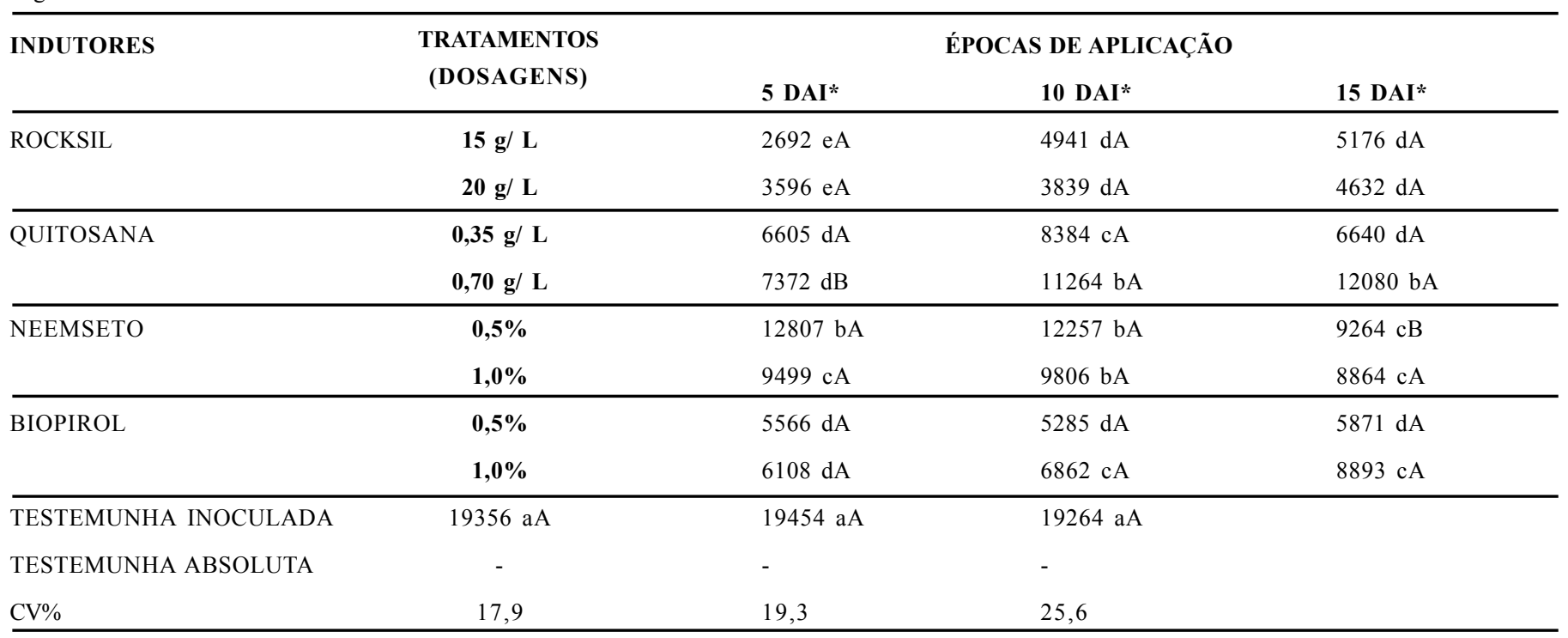

Médias seguidas pela mesma letra minúscula nas colunas e maiúscula nas linhas não diferem estatisticamente entre si pelo teste de Scott-Knott ao nível de $5 \%$ de probabilidade. *DAI - Dias anteriores à inoculação.

incognita, destacando-se com os menores valores tanto para o número de ovos quanto para fator de reprodução (Figura 1). Dutra (9) estudou o efeito de indutores silicatados sobre o parasitismo de Meloidogyne spp. em tomateiros e demonstrou que diferentes doses de silicato de cálcio e silicato de potássio reduziram a reprodução do nematóide e o número de $\mathrm{J} 2$ no solo. Oliveira (16) avaliando o efeito do silicato de cálcio e magnésio em tomateiro verificou que doses de 1,28 e 2,56 g/ $\mathrm{dm}^{3}$ do composto no solo reduziram significativamente o número de ovos de $M$. javanica em relação à testemunha.

Pouco se sabe a respeito do mecanismo de supressão do patógeno pelo hospedeiro, com adição de Si no meio, contudo, existe a hipótese de que o Si estimula os mecanismos naturais de defesa da planta, como por exemplo, a produção de compostos fenólicos, quitinases, peroxidades e acúmulo de lignina $(5,10,17)$.

Os indutores Quitosana na maior dosagem, aplicada aos 5 DAI e o Neemseto na menor dosagem, aplicado aos 15 DAI, apresentaram menor efeito no controle do fitonematóide. Contudo, ambos deferiram estatisticamente da testemunha inoculada, apresentando menor número de ovos (Tabela 2). Serra et al.(20) avaliando o efeito da quitosana no controle de $M$. incognita em alface orgânico, observaram que esse indutor foi eficiente em reduzir o numero de ovos e conseqüentemente o fator de reprodução do patógeno. Kumar \& Kaana (15) aplicando 
Tabela 3: Efeito dos produtos naturais sobre o fator de reprodução 30 dias após a inoculação de Meloidogyne incognita em plantas de tomate orgânico.

\begin{tabular}{|c|c|c|c|c|}
\hline \multirow[t]{2}{*}{ INDUTORES } & \multirow{2}{*}{$\begin{array}{c}\text { TRATAMENTOS } \\
\text { (DOSAGENS) }\end{array}$} & \multicolumn{3}{|c|}{ ÉPOCAS DE APLICAÇÃO } \\
\hline & & 5 DAI* & 10 DAI* & 15 DAI* \\
\hline ROCKSIL & $20 \mathrm{~g} / \mathrm{L}$ & $0,72 \mathrm{eA}$ & $0,76 \mathrm{dA}$ & $0,92 \mathrm{dA}$ \\
\hline QUITOSANA & $0,35 \mathrm{~g} / \mathrm{L}$ & $1,32 \mathrm{dA}$ & $1,67 \mathrm{cA}$ & $1,33 \mathrm{dA}$ \\
\hline \multirow[t]{2}{*}{ NEEMSETO } & $0,5 \%$ & $2,56 \mathrm{bA}$ & $2,45 \mathrm{bA}$ & $1,85 \mathrm{cB}$ \\
\hline & $1,0 \%$ & $1,90 \mathrm{cA}$ & $1,96 \mathrm{bA}$ & $1,77 \mathrm{cA}$ \\
\hline \multirow[t]{2}{*}{ BIOPIROL } & $0,5 \%$ & $1,11 \mathrm{dA}$ & $1,05 \mathrm{dA}$ & $1,17 \mathrm{dA}$ \\
\hline & $1,0 \%$ & $1,22 \mathrm{dA}$ & $1,37 \mathrm{cA}$ & $1,77 \mathrm{cA}$ \\
\hline
\end{tabular}

Médias seguidas pela mesma letra minúscula nas colunas e maiúscula nas linhas não diferem estatisticamente entre si pelo teste de Scott-Knott ao nível de $5 \%$ de probabilidade. *DAI - Dias anteriores à inoculação.

diferentes produtos à base de nim sobre tomateiros observaram que todas as formulações testadas suprimiram a multiplicação do nematóide e a formação de galhas nas raízes das plantas.

Entre as épocas de aplicação dos produtos, foi observado que somente a Quitosana e o Neemseto aplicados aos 5 DAI na maior dosagem e aos 15 DAI na menor dosagem, respectivamente, diferiram estatisticamente dos demais, apresentando baixos valores de número de ovos e fator de reprodução, conforme mostram as Tabelas 2 e 3.

Resultados semelhantes a estes foram observados por Serra et al. (20) aplicando Quitosana na dose de $0,35 \mathrm{~g} / \mathrm{L}$ e aos 5 dias antes da inoculação do patógeno, onde observaram que o indutor apresentou os menores índices para o número de ovos e galhas, no patossistema M. incognita x Alface. O modo de ação da quitosana enquanto um indutor de resistência envolve o estímulo para a biossíntese de lignina e lignificação da parede celular, para a produção de quitinases e glucanases, além da síntese de moléculas envolvidas nos caminhos de sinalização intracelular que conduzem à ativação de outras respostas de defesa $(8,23)$.

Inúmeras pesquisas apontam o efeito supressivo do Nim sobre diversos fitopatógenos, o que se atribui à presença de várias substâncias químicas como o azadirachtin, nimbin, salannin, nimbidin, kaempferol, thionemone, entre outras. Tais substâncias apresentam efeitos nematicidas, contudo, são apontadas também como elicitoras de resistência em plantas (19).

O extrato pirolenhoso Biopirol apresentou-se eficiente em reduzir o número de ovos e fator e fator de reprodução de $M$. incognita em tomateiro, destacando-se na menor concentração $(0,5 \%)$ em todas as épocas de aplicação do produto. Esses resultados são bastante relevantes, pois, para este produto existem poucos trabalhos avaliando o seu efeito como indutor de resistência. Corbani (6) estudando o efeito de diferentes dosagens do extrato pirolenhoso em tomateiros parasitados por M. javanica e M. incognita verificou que o produto reduziu significativamente a quantidade do inóculo inicial do patógeno e a formação de galhas nas raízes das plantas.

Todos os tratamentos se mostraram eficientes em impedir incrementos no inóculo inicial do patógeno, a exemplo do Rocksil.
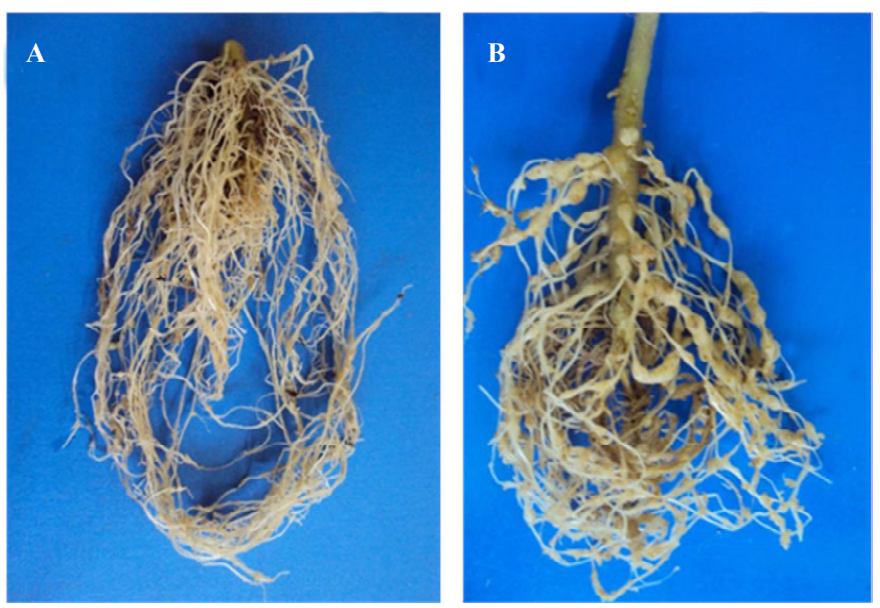

Figura 1. Sintoma de galhas em raízes de tomate resultantes do parasitismo de Meloidogyne incognita. A - Raiz tratada com Rocksil; B - Testemunha.

Contudo, estes apresentaram, na maioria das vezes, baixo desenvolvimento vegetativo refletido no peso da parte aérea sugerindo que houve um custo adaptativo da resistência. De acordo com Kuhn \& Pascholati (14) as plantas apresentam um sistema de defesa latente, com a finalidade de economizar energia e substrato, que pode ser ativado com a chegada do patógeno, ao contrário da resistência constitutiva, que representa um custo real para a planta, uma vez que independente da presença do patógeno, a planta investe seus limitados recursos na produção de defesas. Plantas que investem seus recursos para se defenderem na ausência de patógenos arcarão com custos que refletirão na produtividade, uma vez que as alterações metabólicas que levaram a resistência têm um custo adaptativo associado (11). Assim sendo, a descoberta da melhor época de indução deve ser estudada para cada cultura, evitando-se assim perdas referentes ao custo que a resistência induzida pode demandar. 
Com estes resultados sugere-se que os produtos naturais possam ser base para o desenvolvimento de tecnologias alternativas a serem utilizadas no controle sustentável da meloidoginose em hortaliças.

\section{AGRADECIMENTOS}

Ao Conselho Nacional de Desenvolvimento Científico e Tecnológico $(\mathrm{CNPq})$ pela concessão da Bolsa de Iniciação Científica que gerou este trabalho. A empresa LIA Indústria e Comercio Ltda em nos disponibilizar o produto Rocksil ${ }^{\circledR}$ e a Biocarpo Ltda pelo fornecimento do Biopirol ${ }^{\circledR}$.

\section{REFERÊNCIAS BIBLIOGRÁFICAS}

1. Abreu, R. Brasil tem a $2^{\mathrm{a}}$ maior área de orgânicos do mundo. Agência Brasil, 2005. Disponível em: <http :// www.brasiloeste.com.br/noticia/1424/agricultura-organica $>$. Acesso em: 12 dez. 2010.

2. AgRianUal 2008: Anuário da Agricultura Brasileira. São Paulo, p.43-52, 2008.

3. Assunção, A.; Santos, L.C.; Rocha, M.R.; Reis, A.J.S.; Teixeira, R.A.; Lima, F.S.O. Efeito de Indutores de Resistência sobre $M e$ loidogyne incognita em Cana-de-açúcar (Saccharum spp.). Nematologia Brasileira, Campinas, v.34, n.1, p.56-62, 2010.

4. Bonaldo, S.M.; Schwan-Estrada, K.R.F.; Stangarlin, J.R.; Cruz, M.E.S; Fioro-Tutida, A.C.G. Contribuição ao estudo das atividades antifúngica e elicitora de fitoalexinas em sorgo e soja por eucalipto (Eucalyptus citriodora). Summa Phytopathologica, Botucatu, v.35, n.3, p.383-387, 2007.

5. Chérif, M.; Asselin, A.; Bélanger., R.R. Defense responses induced by soluble silicon in cucumber roots infected by Pythium spp. Phythopathology, St. Paul, v.84, n.3, p.236-242, 1994.

6. Corbani, R.Z. Estudo do extrato pirolenhoso Biopirol ${ }^{\circledR}$ no manejo de nematóides em cana-de-açúcar, olerícolas e citros, em diferentes ambientes. 2008. 55f. Tese (Doutorado em Produção Vegetal) - Faculdade de Ciências Agrárias e Veterinária, Universidade Estadual Paulista, Jaboticabal.

7. Costa, M.B.B.; Campanhola, C. Agricultura alternativa no estado de São Paulo. Jagrariúna: Embrapa - CNPMA, 1997. $63 \mathrm{p}$.

8. DI Piero, R.M.; Garda, M.V. Quitosana reduz a severidade da antracnose e aumenta a atividade de glucanase em feijoeiro-comum. Pesquisa Agropecuária Brasileira, Brasília, v.43, p.215$221,2008$.

9. Dutra, M.R. Controle de nematóide das galhas (Meloidogyne spp.) com silicatos em feijoeiro (Phaseolus vulgaris L.), tomateiro (Licopersicon esculentum Mill) e cafeeiro (Coffea arábica L.). 2004. 110f. Tese (Doutorado em Fitopatologia) Universidade Federal de Lavras, Lavras.

10. Fawe, A.; Abou-zaid, M.; Menzies, J.G.; Bélanger, R.R. Silicon mediated accumulation of flavonoid phytoalexins in cucumber. Phytopathology, St. Paul, v.88, n.5, p.396-401, 1998.

11. Iriti, M.; F. Faoro, F. Does benzothiadiazole-induced resistance increase fitness cost in bean? Journal of Plant Pathology, Piso, v. 85, n. 4, p. $265-270,2003$

12. Hussey, R.S.; Barker, K.R. A comparison of methods of collecting inocula of Meloidogyne spp. including a new technique. Plant Disease Reporter, Washington, v.57, p.1025-1028, 1973.

13. Khan, T.A.; Saxena, S.K. Integrated management of root knot nematode Meloidogyne javanica infecting tomato using organic materials and Paecilomyces lilacinus. Bioresource Technology, Essex, v. 61, p. 247-250, 1997.

14. Kuhn, O.J.; Pascholati, S.F. Custo Adaptativo da resistência induzida no controle de fitopatógenos. In: Rodrigues, F.A.; Romeiro, R.S. Indução de resistência em plantas a patógenos. Viçosa: Universidade Federal de Viçosa, 2007. v.1, cap.4, p.67-90.

15. Kumar, S.; Khaana, A.S. Effect of neem-based products on the root-knot nematode, Meloidogyne incognita, and growth of tomato. Nematologia Mediterranea, Pisa, v.34, p.141-146, 2006.

16. Oliveira, R.M. Silicato de cálcio e magnésio no controle de Meloidogyne javanica e no desenvolvimento de mudas de bananeira-prata anã. 2009. 47f. Dissertação (Mestrado em Produção Vegetal) - Unimontes, Montes Claros.

17. Reis, T.P.H. O silício na agricultura. Lavras: Universidade Federal de Lavras, 2006. 99 p.

18. Salgado, S.M.L.; Silva, L.H.C.P. Potencial da indução de resistência no controle de fitonematóides. In: Cavalcanti, L.S.; DI Pietro, R.M.; Pascholati, S.F.; Resende, M.L.V.; Romeiro, R.S. Indução de resistência em plantas a patógenos e insetos. Piracicaba: FEALQ, 2005. v.1, cap.8, p. 155-168.

19. Schmutterer, H. The Neem Tree, source of unique products for integrated pest manegement, medicine, industry and other purposes. Cambridge: $\mathrm{VCH}, 1995.696 \mathrm{p}$.

20. Serra, I.M.R.S., G.S. Silva, I.C.M. Ferreira. Efeito de indutores naturais de resistência sobre Meloidogyne incognita em alface cultivada em sistema orgânico. Tropical Plant Pathology, Brasília, v. 33, p.S112, 2008. Suplemento.

21. Silva, G.S. Ocorrência e controle de fitonematóides no feijão caupi no Meio-Norte do Brasil. In: Cardoso, M.J. A cultura do feijão caupi no Meio-Norte. Teresina: Embrapa, 2000. v.1, cap.8, p. 229-236.

22. Pascholati, S.F.; Toffano, L. Indução de resistência contra fitopatógenos em espécies arbóreas. In: Rodrigues, F.A.; Romeiro, R.S. Indução de resistência em plantas a patógenos. Viçosa: Universidade Federal de Viçosa, 2007. v.1, cap.3, p.59-66.

23. Vander, P.; Varum, K.M.; Domard, A.; EL Gueddari, N.E.; Moerschbacher, B.M. Comparison of the ability of partially N-acetylated chitosans and chitooligosaccharides to elicit resistance reactions in wheat leaves. Plant Pathology, Oxford, v.118, p.1353$1359,1998$. 